\title{
Ecological community dynamics: 20 years of moth sampling reveals the importance of generalists for community stability
}

Carvalho, Gary; Seymour, Mathew; Brown, Nigel; Wood, Courtney ; Goertz, Sarah; de Bruyn, Mark

\section{Basic and Applied Ecology}

\section{Published: 01/12/2020}

Peer reviewed version

Cyswllt i'r cyhoeddiad / Link to publication

Dyfyniad o'r fersiwn a gyhoeddwyd / Citation for published version (APA):

Carvalho, G., Seymour, M., Brown, N., Wood, C., Goertz, S., \& de Bruyn, M. (2020). Ecological community dynamics: 20 years of moth sampling reveals the importance of generalists for community stability. Basic and Applied Ecology, 49, 34-44.

https://www.sciencedirect.com/science/article/pii/S1439179120301195

\footnotetext{
Hawliau Cyffredinol / General rights

Copyright and moral rights for the publications made accessible in the public portal are retained by the authors and/or other copyright owners and it is a condition of accessing publications that users recognise and abide by the legal requirements associated with these rights.

- Users may download and print one copy of any publication from the public portal for the purpose of private study or research.

- You may not further distribute the material or use it for any profit-making activity or commercial gain

- You may freely distribute the URL identifying the publication in the public portal ?
}

Take down policy

If you believe that this document breaches copyright please contact us providing details, and we will remove access to the work immediately and investigate your claim. 


\section{Journal Pre-proof}

Ecological community dynamics: 20 years of moth sampling reveals the importance of generalists for community stability

Mathew Seymour, Nigel Brown, Gary R Carvalho,

Courtney Wood, Sarah Goertz, Nathan Lo, Mark de Bruyn

PII:

S1439-1791(20)30119-5

DOI:

https://doi.org/10.1016/j.baae.2020.11.002

Reference:

BAAE 51293

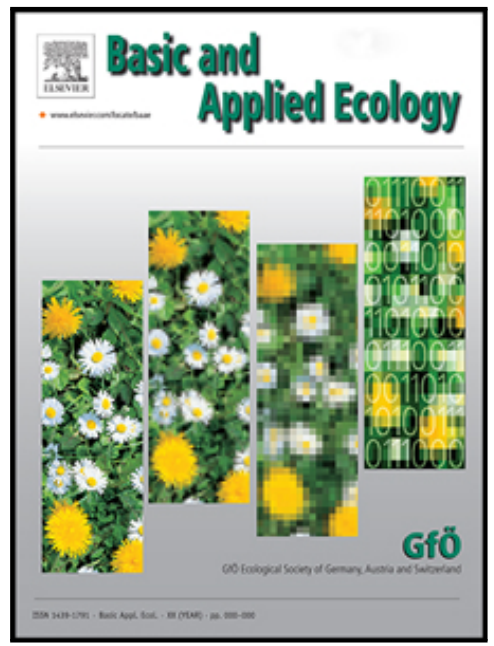

To appear in:

Basic and Applied Ecology

Received date: 26 March 2020

Accepted date: $\quad 17$ November 2020

Please cite this article as: Mathew Seymour, Nigel Brown, Gary R Carvalho, Courtney Wood, Sarah Goertz, Nathan Lo, Mark de Bruyn , Ecological community dynamics: 20 years of moth sampling reveals the importance of generalists for community stability, Basic and Applied Ecology (2020), doi: https://doi.org/10.1016/j.baae.2020.11.002

This is a PDF file of an article that has undergone enhancements after acceptance, such as the addition of a cover page and metadata, and formatting for readability, but it is not yet the definitive version of record. This version will undergo additional copyediting, typesetting and review before it is published in its final form, but we are providing this version to give early visibility of the article. Please note that, during the production process, errors may be discovered which could affect the content, and all legal disclaimers that apply to the journal pertain.

(C) 2020 Published by Elsevier GmbH on behalf of Gesellschaft fx00FC;r x00D6;kologie. 
Running Head: Lepidoptera community stability

Ecological community dynamics: 20 years of moth sampling reveals the importance of generalists for community stability

Authors: Seymour Mathew ${ }_{-}^{\mathrm{a}}$, Brown Nigel $^{\mathrm{b}}$, Carvalho Gary $\mathrm{R}^{\mathrm{b}}$, Wood Courtney ${ }^{\mathrm{c}}$, Goertz Sarah $^{\text {b,d }}$, Lo Nathan ${ }^{\mathrm{c}}$, de Bruyn Mark ${ }^{\mathrm{b}, \mathrm{c}_{*}}$

${ }^{a}$ Department of Ecology, Swedish University of Agricultura1 Sciences, Uppsala, Sweden

${ }^{\mathrm{b}}$ School of Natural Sciences, Bangor University, Bangor, Gwynedd LL57 2UW, UK

${ }^{c}$ The University of Sydney, School of Life and Environmental Sciences, Sydney, NSW 2006,

Australia

${ }^{\mathrm{d}}$ School of Life Sciences, The University of Nottingham, Nottingham NG7 2UH, UK

* Mark de Bruyn. E-mail address: mark.debruyn@sydney.edu.au

* Mathew Seymour. E-mail: mathew.seymour@slu.se 


\begin{abstract}
Species diversity is presently declining and homogenizing globally due to human land use changes and climate change effects. However, the causes of these declines are difficult to determine due to complex ecological interactions. Lepidopterans are a diverse and ecologically important group of insects that are declining in Britain and other parts of Europe. Long-term monitoring data made available in 2003 showed that $66 \%$ of observed species declined over the course of 35 years, however, it is not known what effect species losses has on ecosystem stability. Here, we assess long-term moth diversity dynamics in relation to climatic shifts over 20 years, and investigate the importance of stability in maintaining and conserving ecological communities. From 1993 to 2014, moth species data and abundances were recorded over 7,390 trapping nights. Overall, 376 species were recorded over 20 -years, identifying seasonal and annual trends in species richness strongly associated with oscillations in temperature. Long-term stability, measured using mean-rank shifts and temporal variability, was indicative of significant positive associations between species diversity and temperature. Using rank shift analyses we were able to not only assess community stability dynamics, but also the individual species dynamics and their contribution to community diversity over time. We also noted generalist feeders were more associated with maintaining diverse species communities subjected to oscillating climatic conditions compared to specialist taxa. Overall, our study shows the benefit of utilizing community-based stability assessments to distil population level information from complex datasets, highlighting the need for long-term monitoring at the community level to explore impacts of environmental change on ecosystem function.
\end{abstract}

Keywords: rank shift; biodiversity; Lepidoptera; refugia; Long-term monitoring 


\section{Introduction}

Biodiversity represents a fundamental metric of ecosystem health (Gotelli \& Colwell, 2001) and is closely linked to environmental stability and sensitivity (Oliver et al., 2015). Several factors are attributed to shifts in biodiversity, including alteration of habitat, introduction or extinction of species, and climate change (Hooper et al., 2005). The ongoing Anthropocene extinction event accounts for an estimated 11,000 to 58,000 species lost per year, due to human activity accelerating the natural extinction rate by $100-1000$ times 'normal' background levels (Dirzo et al., 2014; Scheffers et al., 2012). However, processes driving the decline in the majority of extinctions are unclear, particularly in insects where the observed and expected extinction trends vary widely among family groups (Dirzo et al., 2014). Insects, despite being marginal in terms of public interest, are the primary biomass of terrestrial fauna and are vital for many ecosystem services, including those associated with pollination, pest control, disease prevention and carbon cycling (Losey \& Vaughan, 2006). Lepidopterans are a diverse and ecologically important group of insects that are declining in Britain and other parts of Europe. Long-term monitoring data made available in 2003 showed that $66 \%$ of observed species declined over the course of 35 years, exceeding declines in birds and vascular plants (Conrad, Warren, Fox, Parsons, \& Woiwod, 2006; Hill et al., 2002). Lepidoptera are also informative indicators of environmental quality and change (Fleishman \& Murphy, 2009). However, it is unknown what effect species losses have on moth community stability (and associated long-term ecosystem function).

Changes in biological communities can have profound impacts on community stability (Chapin III et al., 2000). Stability of biological communities is a long and well-studied topic in ecology (R. MacArthur, 1955), with much attention on components of stability, including resilience, resistance, persistence, and variability (Donohue et al., 2013, 2016; Hillebrand et al., 
2018). There are many definitions of stability. Here, we define it as the ability of a system to maintain or return to a stable biodiversity state (Chesson, 2000; Donohue et al., 2016). We use 'community stability' such that stable communities are those that experience little to no change in their community composition over time, typically attributed to resistance or resilience of the community composition to perturbations (e.g. climate change). Resistance is in essence the ability of the community to withstand perceived disturbance events, whereas resilience refers to the ability of a community to revert or return to the aforementioned stable state when disturbance causes change to occur. Unstable biological communities, due to poor resilience or resistance, are more susceptible to extinction when disturbances occur, which can lead to loss of ecosystem function and possibly wider impacts on surrounding ecological systems (Hooper et al., 2005).

Species richness, defined as the number of unique species in a given community, is the simplest way to quantify biodiversity, and provides a baseline for comparing seasonal and annual trends in community composition (Connell, 1978; R. H. MacArthur \& Wilson, 1967; Seymour et al., 2020). In general, evidence suggests high species diversity promotes community stability (and ecosystem function) through increased species interactions, increased utilization of the available niche space, and rescue effects (Donohue et al., 2013; Isbell et al., 2009). However, others have suggested stability can decline irrespective of increasing biodiversity when opposing effects on stability are present, such as temperature or flooding (Pennekamp et al., 2018). Studies have also found that environmental variation can impact stability negatively, such that altering environmental conditions also alters the ecologically stable state that communities adjust to (Layer et al., 2010). While species diversity will fluctuate naturally over time due to seasonal, environmental, trophic or random factors, assessment of community stability allows determination of the mechanisms associated with temporal trends in community species 
composition. It continues, therefore, to be paramount that we understand the factors influencing community dynamics in natural environments, particularly those affecting stability over time, enabling assessment of the long-term health of our ecosystems (Hooper et al., 2005). Such temporal assessment requires long-term monitoring studies to rigorously assess the ecosystem impact on biological communities (Franklin, 1989).

Understanding environmental impacts on community stability requires multi-generational studies, making long-term ecological studies of the utmost importance for assessing biodiversity and stability dynamics (Magurran et al., 2010). However, long-term species community data are increasingly rare under current research strategies, and thus correspondingly valuable.

Conservation relies heavily on long-term ecological data for identifying shifts in threatened species, locating geographic hotspots of biodiversity, and in predicting future species distributions due to climatic or habitat shifts (Willis et al., 2007). Principally, there are two main questions long-term data are utilized for: the assessment of turnover, which can be used to infer stability, and changes in biodiversity, often through established diversity indices such as species richness (Magurran et al., 2010). Additional environmental information can then be collected to assist in understanding trends in, and drivers of, stability or diversity over time. The importance of data quality and integrity is key for assessing changes to the environment, and enables effective management of existing natural resources.

Lepidoptera include over 160,000 known species, making it one of the largest insect orders (Kristensen et al., 2007). Moths comprise the dominant subset of the Lepidoptera, accounting for about $88 \%$ of the known Lepidopteran species (Young, 1997). As such, moths are a key biomonitoring group for ecosystem and conservation management (Kerr et al., 2000). The consensus is that additional long-term studies encompassing a breadth of diverse habitats and 
more species are needed to understand the complex interactions of changing ecological conditions on moth communities. Observing large sets of moth species (e.g. 200+ unique species) for the purposes of conservation is a daunting task; however, the use of light traps can make such large-scale sampling possible.

Treborth Botanic Garden is a botanical woodland refugia in North Wales, UK, and represents a haven for biological diversity (Lindenmayer \& Likens, 2009). In contrast to many other long-term monitoring sites, environmental conditions in North Wales have been minimally affected by climatic change, offering an assessment of community stability dynamics on a finer scale compared to previous studies. Additionally, there has been minimal change in landuse in Treborth Botanic Garden since a moth (Lepidoptera) monitoring program began in 1993, offering insights into long-term conservation impacts of refugia habitat. Here, we assess longterm moth diversity dynamics in relation to climatic shifts over the past 20 years, and investigate the importance of stability in maintaining and conserving ecological communities. Our study analyses 7,390 nights of moth recordings from 1993 to 2014, with three main objectives. 1) Does moth community composition, recorded at Treborth Botanic Garden, change over time? 2) Are changes in moth community composition related to environmental changes over time? 3) Are there changes in stability of the Treborth Botanic Garden moth community in relation to life history characteristics? The over-arching goal of this study was to understand the long-term impacts of seasonal and annual shifts in recurring moth community dynamics, and the underlying population dynamics.

\section{Materials and methods}

\section{Data collection}


Treborth Botanic Garden is located in North Wales, UK, and includes a rocky coastal shoreline, 30 acres of high-canopy forest, and semi-natural grasslands. The woodland at Treborth Botanic Garden is mixed with areas of high canopy oak-ash woodland and areas of younger birch and willow dominated wood, with a few small 70-year-old conifer plantations. The grasslands at Treborth Botanic Garden are semi-natural mesotrophic grasslands (MG5 according to the National Vegetation Classification) and actually contain more species of higher plant than the woodlands. Areas of the grassland are treated as 'hay-meadows' and left uncut until late summer.

From 1993 to 2014, nightly (but see below) macro-moth (henceforth referred to as moth) species diversity and abundance were recorded at dawn, using a Robinson's Light Trap (with 125 watt Mercury Vapor Lamp) (coordinates: 53.216348, -4.172762). Trapping was carried out nightly, whenever possible, by a single individual (Nigel Brown) to ensure consistency of identification, with traps set before dark. The only exceptions were when strong winds or very heavy rain posed a threat to the safety of the moth trap and associated electrics. Snowfall was a rare event and only affected trapping a handful of times. Additionally, minor equipment failures account for approximately 30 missing nights over the study period. The trap was positioned at a single location so that it sampled moths from both woodland and grassland habitats. Moths were released at the same location as where they were trapped. Data collected included species present, number of individuals per species, total number of species and total number of individuals. Treborth Botanic Garden is a coastal site with a benign climate - c.1050 mm rain per year, with mild winters and warm but not excessively hot summers. Minimum and maximum air temperatures, current (9 am) temperatures, cloud cover, wind speed and direction, and rainfall for the previous 24 hours were recorded daily at 9 am in a Stevenson Screen. Daily moth data were catalogued and summed for each month, and standardized across year, for subsequent 
analyses (Borcard et al., 2011). Given the common unevenness in sampling effort over such long-term studies, it is important to standardize such datasets or convert to presence/absence data (Borcard et al., 2011). Therefore, the data we standardized the data using a Hellinger transformation for analyses that required abundance data, otherwise presence/absence data were used to measure moth community composition (Borcard et al., 2011). Species were grouped into monophagous/oligophagous (specialist) if they fed exclusively on a single host plant or if they fed on host plants within a single family, and polyphagous (generalist) if they fed on host plants across multiple family groups (Cates, 1980; Waring \& Townsend, 2017).

\section{Statistical analyses}

All statistical analyses used the program R, version 3.5.1 (R Core Team, 2019). Temporal trends in moth diversity patterns in relation to environmental variables were assessed using generalized additive models (GAMs), using the R-package mgev (Wood, 2011). We assessed the change in monthly moth species richness, Fisher's alpha and Shannon diversity index (H'), in response to temperature over time using average monthly temperature nested in month per year, as a smoothing term, to account for the nonlinear temporal relationship (each diversity metric modeled separately). The structure for each model was; Diversity measure $\sim \mathrm{s}$ (Year, Month, Temperature).

To assess whether moth observation counts and subsequent species richness was related to mean temperature across years were assessed the linear relationship between total counts, species richness and rarefied species richness against mean temperature using the $\mathrm{lm}$ function in $\mathrm{R}$. For the rarefaction analyses we rarefied each month to the lowest observed number across all year, simulation the rarefaction 1000 times to assess the variability in the analyses. 
We assessed changes in stability over time using rank clocks and mean rank shift in species between years, following Collins et al. (2008). Rank clocks are similar to rankabundance curves and allow for analysis and visualization of internal population changes in abundance data. Mean rank shift statistics summarize the temporal change in rank clocks, providing an assessment of community stability over time. For each year, species were ranked based on abundance, with ranks standardized for each year to allow comparison between years and to account for variation in sampling across time.

Lastly, we assessed the change in stability over time, using three measures of stability; 1) mean rank shift (Collins et al., 2008), 2) temporal stability (Tilman et al., 2006) and 3) compositional turnover (Donohue et al., 2013) in relation to species richness and feeding strategy (generalist/specialist) using linear regression. Mean rank shift quantifies changes in rank abundances between years, reflecting temporal shifts in abundance and ecosystem function calculated as

$$
\text { Mean Rank } k_{t+1} \text { Shift }=\sum_{i=1}^{n}\left(\left|R_{i, t+1}-R_{i, t}\right|\right) / n
$$

where $n$ is the number of species common in year $t$ and year $t+1 . R$ is the normalized rank of species $i$ in year $t$. Temporal stability was quantified as the coefficient of variance of log species abundances over time (Tilman et al., 2006). Composition turnover was calculated as the turnover partition of the Jaccard similarity index (Baselga, 2010; Donohue et al., 2013). We calculated stability for the community as a whole, and for each set of generalist and specialist communities to compare trends against species richness and temperature using linear regression. Linear models were assessed using a model selection approach, and Akaike information criterion (AIC) to compare models, starting from the full model of Stability $\sim$ richness $\mathrm{x}$ feeding group + 
richness $\mathrm{x}$ temperature down to Stability $\sim 1$, using the function stepAIC in $\mathrm{R}$ with direction set to "both" (model selection in both directions).

\section{Results}

At Treborth Botanic Garden, neither mean annual temperature, rainfall nor hours of sunlight from 1993 to 2014 showed clear upward or downward annual trends. Mean monthly temperature, across all years (1993 to 2014), ranged between $9.50 \pm 4.96{ }^{\circ} \mathrm{C}$ in 2010 to $11.02 \pm$ $3.54{ }^{\circ} \mathrm{C}$ in 2009 . Mean monthly rainfall ranged from $670 \pm 27 \mathrm{~mm}$ in 1996 to $1117 \pm 55 \mathrm{~mm}$ in 2000. Mean hours of daily sunlight per month ranged from $3.76 \pm 1.82$ in 2012 to $4.87 \pm 2.64$ in 1995.

Overall, we recorded 376 species across 11 moth families, primarily from Geometridae (153 species) and Noctuidae (176 species) (Table 1; Appendix A), from 7,390 trapping nights (representing $89 \%$ of all possible sampling occasions). A few groups posed some identification problems generally, e.g. Hoplodrina blanda and H. octogenaria, and the genus Epirrita (which we recorded as Epirrita sp.), however these did not influence the results presented below. Worn specimens were often disregarded if there was doubt over their identity or were aggregated - the most common example of that is Eupithecia sp. For clarification, aggregated groups were not identified to species level and were not included in any subsequent analysis. Total annual species richness varied from 222 species in 2010 to 264 in 1995, averaging $243 \pm 13$ species recorded across all years. Species richness peaked in summer $(131 \pm 15)$, generally in August except for 1993, 1997, and 2009, where peak species richness occurred in July. Species richness was lowest during winter (5 \pm 3), generally observed February except for 1993, 1998, 1999, 2006 and 2007, when it was observed in January. Shannon diversity ranged from 1.41 in 1997 to 2.6 in 1993 , averaging $2.36 \pm 0.23$ across all years. Fisher's alpha ranged from 8.9 in 1996 to 12.07 in 2006, 
averaging $11.05 \pm 0.74$ across all years. Generalist species predominated the site, accounting for $70 \%( \pm 11)$ of species richness across all years (see Appendix B: Fig. B.1). We found temporal and seasonal increases in moth species richness significantly corresponded with increases in mean annual temperature following our GAM model fitting (P-value $<0.001 ; \mathrm{R}^{2}=0.917$; Fig. 1 ; Table 2). We also found increases in Fisher's alpha and Shannon diversity to significantly correspond with increases in mean temperature (Fisher's alpha: $\mathrm{P}$-value $<0.001 ; \mathrm{R}^{2}=0.922$, Shannon diversity: P-value $<0.001 ; \mathrm{R}^{2}=0.753 ;$ Fig. 1 ; Table 2).

We found no significant effect of moth observation counts related to temperature ( $p$-value $=0.814, \mathrm{R}^{2}=0.003$ ), a significant positive effect of mean annual temperature on observed mean species richness in ( $p$-value $\left.=0.038, R^{2}=0.208\right)$ and an average significant positive effect of mean annual temperature on rarefied mean species richness across the 1000 replications (mean $\mathrm{p}$-value $=0.006$, mean $\left.\mathrm{R}^{2}=0.360\right)($ Appendix B. Fig. B.2).

In general, dominant and very rare species maintained their respective ranks across all years compared to middle ranked species, which differed widely in their rank assignment from year to year (Fig. 2; Appendix C). The dominant species recorded for most years was the Large Yellow Underwing (Noctua pronuba), a generalist herbaceous feeder that is widespread across the British Isles (mean annual rank $=1.2 \pm 0.4$ ). Other dominant species included the Common Marbled Carpet (Dysstroma truncata; mean annual rank 5.3 \pm 3.0 ), Heart \& Dart (Agrotis exclamationis: mean annual rank $=5.4 \pm 6.7)$, Common Quaker $($ Orthosia cerasi ; mean annual rank $5.8 \pm 5.1$ ) and the Mottled Beauty (Alcis repandata; mean annual rank $=7.6 \pm 4.4$ ), all of which are common across the British Isles. Highly variable species, those that were common in some years and rare or absent in others were sampled throughout the monitoring period. Examples include the Dingy Footman (Eilema griseola; mean annual rank $=116.9 \pm 118.2$, 
southerly species), Buff Footman (Eilema depressa; mean annual rank $=111.9 \pm 109.5$, southerly species), August Thorn (Ennomos quercinaria; mean annual rank 107.5 \pm 85.6 , found locally across British Isles), Dark Marbled Carpet (Dysstroma citrata; mean annual rank $=205.4$ \pm 74.9 , found across British Isles, localized in the south), and Blair's Shoulder-knot (Lithophane leautieri; mean annual rank $=152.4 \pm 74.3$, recent colonist now common across the British Isles). A full list of species entering and leaving the site between subsequent years is available in Appendix D.

Notable Lepidoptera species declines at Treborth Botanic Garden include the Common Swift (Korscheltellus lupulina), which ranked $73^{\text {rd }}$ in 1998 and declined to $140^{\text {th }}$ in 2007 before becoming very rare, with limited recordings thereafter and only a single recorded individual in 2013. Generally considered common throughout Britain, with greater abundances in the southern regions (Waring \& Townsend, 2017), it is unclear why this species declined rapidly at Treborth Botanic Garden. The Shoulder-striped Wainscot (Leucania comma) is another notable declining species, having peaked in abundance in 1993 at $46^{\text {th }}$ and going unobserved in 2005 to being observed sparingly ( $<10$ individuals per year) since 2007 . While the species is common throughout Britain, records outside of Ireland suggest the species is sparsely distributed (Waring \& Townsend, 2017). Similarly, the Bright-line Brown-eye (Lacanobia oleracea) has declined since peaking at $65^{\text {th }}$ in 1995 to potential local extinction in 2007, with single digit recordings since 2009, despite being quite common throughout Britain. The Buff-tip (Phalera bucephala) is one species that shows a series of declines and increases, peaking in 1993 at $47^{\text {th }}$ and falling the next year to $183^{\text {rd }}$ before slowly rebounding to $63^{\text {rd }}$ in 2006 and crashing again in 2011, with rare sightings thereafter. Other species with oscillating rank dynamics include the Burnished Brass (Diachysia chrysitis), the Buff Arches (Habrosyne pyritoides), the Smoky Wainscot (Mythimna 
impure), and the Bright-line Brown-eye (Lacanobia oleracea) (Appendix B. Fig. B.3; Appendix D).

Stability measured via mean rank shift statistics showed a significant positive correlation with species richness $(\mathrm{p}=0.029)$ and feeding group $(\mathrm{p}=0.003)$ (Fig. 3A; Table 3) and a nonsignificant relationship with mean annual temperature $(\mathrm{p}=0.133$; Table 3$)$. Temporal variability showed significant positive correlations with species richness $(\mathrm{p}=0.001)$, with greater stability for generalist versus specialist ( $p<0.001$ ) (Fig. 3B; Table 3) and non-significant effects of temperature ( $\mathrm{p}=0.1$; Table 3 ). Stability measured as compositional turnover showed no significant relationship with species richness $(\mathrm{p}=0.553)$ with generalist stability being greater than specialist $(\mathrm{p}<0.001)$ (Fig. 3C; Table 3) and a non-significant feeding group $\mathrm{x}$ species richness interaction ( $\mathrm{p}=0.89$; Table 3). Model selection for each test and AIC scores can be found in Appendix E.

Mean species ranks varied most among species that occupied middle rankings (Fig. 4). Dominant ranked species showed lower variance in mean ranks over the entire 20 -year observation and were mostly polyphagous. Rare species were consistently rare and showed lower variation in mean rank assignment compared to middle ranked species, resulting in an overall positively skewed unimodal distribution between mean species rank and mean rank variation (Fig. 4).

\section{Discussion}

Here we present the findings from a long-term Lepidopteran monitoring program. Overall, 376 species were recorded nightly, with minimal interruption, over a 20-year period with several notable changes in species level abundances. Community stability shows some fluctuations, but is stable over the long-term, with stability between subsequent years (i.e. 
resilience) associated with higher levels of biodiversity. Interestingly, the presence of generalist, polyphagous species was observed to be an important component for community stability and biodiversity, compared to the lesser, though still positive effect of specialist (monophagous/oligophagous) species over time. While temperature change was minimal over the 20 -year period, there was a clear relationship between temperature and moth diversity patterns, suggesting a positive significant association between increasing temperatures and lepidopteran richness.

Lepidopteran species that were most abundant at Treborth Botanic Garden generally remained dominant throughout the study duration. Notable species with extreme shifts in rank abundance were the Dingy Footman (Eilema griseola), which rose from a rank of 231 in 2000 to the $2^{\text {nd }}$ most abundant species in 2008 and the Buff Footman (Eilema depressa) which increased from 188 in 2000 to $12^{\text {th }}$ in 2008 . Both species are algae and lichen feeders, which is an uncommon feeding strategy for British Lepidopterans ( $<1 \%$ of known species) compared to predominantly leaf or bud feeding ( $\sim 78 \%$ of British macro-moths) (Young, 1997). The insurgence of the Dingy Footman and Buff Footman may coincide with the ongoing environmental recovery from acidic pollutants, via the implementation of 'Clean Air' Acts introduced in the 1970 s and ' 80 s, which are known to adversely affect bryophytes and lichens (Botham et al., 2015). The Blair's Shoulder-knot (Lithophane leautieri) was not observed in 1993 but rose to $70^{\text {th }}$ most abundant in 2012 , which may correspond to their recent switch in food plants to ornamental garden versions of Cupressaceae conifers and UK expansion northward since around the 1950s (Owen \& Duthie, 1982).

Concerning more general community stability dynamics, we found generalist species (polyphagous feeders) to be more indicative for maintaining inter-annual ecosystem stability and 
higher overall biodiversity compared to specialist species (oligophagous/monophagous feeders). Whereas generalist characteristics are often associated with invasive or pest species (Bebber et al., 2014; e.g. Seymour et al., 2016), non-resident generalist species were rare in this study and did not dominate the moth communities. These findings contradict theoretical expectations that specialists promote species diversity through wider niche utilization (Clavel et al., 2011). However, while the importance of generalists is often downplayed due to their unclear or lesser functional contributions, compared to specialists, they may serve an important role in maintaining local species diversity pools in their response to disturbance, to which they are generally more adaptable (Hooper et al., 2005; Kitahara \& Fujii, 1994). Given that natural environments do vary annually, even in semi-stable conditions such as Treborth Botanic Garden, specialists may periodically be at a disadvantage compared to generalists.

Overall, higher temperatures corresponded significantly with greater species diversity. Despite the projected long-term decline in biodiversity under current climate change projections, at least for the short term, insect herbivore abundance and activity has been observed and is expected to increase (Bale et al., 2002; Bebber et al., 2014). Increased lepidopteran diversity as an effect of increased temperature is potentially a result of range shifts of previously southern restricted species overlapping with established populations, potentially resulting in displacement of resident species if warming trends continue (Chen et al., 2011). The expected temperature increase is predicted to promote the expansion of several moth species, particularly those adapted to generalist lifestyles, at least temporarily, through increased flight activity (dispersal and movement) (Bebber et al., 2014). However, while warmer temperatures are expected to increase insect biodiversity, there is an ongoing observed decline in moth species diversity across Britain, associated with habitat destruction and habitat homogenization (Fox, 2013). That we find stable 
community dynamics at Treborth Botanic Garden, a relatively small conservation area, is encouraging, and indicates lepidopteran diversity recovery from opposing stability factors occurs with 1-2 years. Such findings are in contrast to other observational studies (Conrad et al., 2006; Franzén \& Johannesson, 2007; Groenendijk \& Ellis, 2011), where a 27 - 71\% loss of resident moth species is reported for non-refugia habitat.

Overall, stability of the lepidopteran community is positively associated with increased biodiversity (Fig. 3), indicating that underlying seasonal resilience dynamics (between year stability) are potentially related to the previous year's biodiversity. While generalist species contributed primarily to the stability of the community, diversity in general promoted stability as a whole. Increased species richness is generally expected to increase stability, but may become saturated at least under experimental settings (Pennekamp et al., 2018). Here, we observed that increased temperature corresponded with increased species diversity, which in turn also corresponded with increased community stability of the preceding year. In essence, while temperature influences the ability of the community to accumulate species diversity throughout the current year, the biodiversity of the previous year provides the starting species pool for that current year. Interestingly, the starting species pool is dominated by a similar set of species across the monitoring period (Fig. 2), which have been largely generalists over the course of this study. The observed variation in species diversity from year to year is driven largely by the midrange abundance species, with rare species never being a major component of the overall stability of the community.

Moth ecology is insightful in studying such stability cycles, since the system is constantly in a state of seasonal instability and transitioning to alternative stable states throughout the year. Likewise, the high ecological and developmental diversity of Lepidopteran communities renders 
single species studies inaccurate indicators of environmental shifts. Observations at the community level, however, provide a powerful, cost-effective and non-invasive biomonitoring tool. Annual monitoring of community stability dynamics can yield integrated measures of environmental change on community composition and ecosystem functioning. Here we show that applying stability concepts to long-term community data dynamics assists in elucidating the underlying factors contributing to changes in ecosystem functioning. We also highlight the importance of refugia habitats, such as Treborth Botanic Garden, in buffering detrimental longterm declines in moth communities documented elsewhere (Clavel et al., 2011; Dennis et al., 2019; Keppel et al., 2012). Natural repositories continues to represent valuable resources for long-term conservation monitoring, and provides a platform for early detection of environmental effects on changes to insect phenology (Usher \& Keiller, 1998). Long-term ecological studies are critical for underpinning sustainable management and conservation of natural capital, and for investigating the determinants and dynamics of their resident species.

\section{Acknowledgements}

We thank the Friends of Treborth Botanic Garden for their efforts in sampling and for maintaining the grounds not only for this project, but also for the wider public benefit. We thank The University of Sydney for funding from a Denison Summer Scholarship to Courtney Wood.

Author Contributions: NB conceived and designed the study. NB collected the samples. MS, CR, CW and SG analyzed the data. MdB, GRC, NL and NB supervised the research. MS wrote the manuscript; all other authors provided input and editorial advice. 
Appendix A. Supplementary data

Appendix B. Supplementary data

Appendix C. Supplementary data

Appendix D. Supplementary data

Appendix E. Supplementary data

Supplementary data associated with this article can be found, in the online version, at XXXXX. 


\section{References}

Bale, J. S., Masters, G. J., Hodkinson, I. D., Awmack, C., Bezemer, T. M., Brown, V. K., Butterfield, J., Buse, A., Coulson, J. C., Farrar, J., Good, J. E. G., Harrington, R., Hartley, S., Jones, T. H., Lindroth, R. L., Press, M. C., Symrnioudis, I., Watt, A. D., \& Whittaker, J. B. (2002). Herbivory in global climate change research: direct effects of rising temperature on insect herbivores. Global Change Biology, 8(1), 1-16. http://dx.doi.org/10.1046/j.13652486.2002.00451.x

Baselga, A. (2010). Partitioning the turnover and nestedness components of beta diversity. Global Ecology and Biogeography, 19(1), 134-143. https://doi.org/10.1111/j.14668238.2009.00490.x

Bebber, D. P., Holmes, T., \& Gurr, S. J. (2014). The global spread of crop pests and pathogens. Global Ecology and Biogeography, 23(12), 1398-1407. https://doi.org/10.1111/geb.12214

Borcard, D., Gillet, F., \& Legendre, P. (2011). Numerical Ecology with R. Springer.

Botham, M. S., August, T. A., Pescott, O. L., Simkin, J. M., Randle, Z., \& Dore, A. J. (2015). Air pollution and its effects on lichens, bryophytes, and lichen-feeding Lepidoptera: review and evidence from biological records. Biological Journal of the Linnean Society, 115(3), 611-635. https://doi.org/10.1111/bij.12541

Cates, R. G. (1980). Feeding patterns of monophagous, oligophagous, and polyphagous insect herbivores: The effect of resource abundance and plant chemistry. Oecologia, 46(1), 22-31. https://doi.org/10.1007/BF00346961

Chapin III, F. S., Zavaleta, E. S., Eviner, V. T., Naylor, R. L., Vitousek, P. M., Reynolds, H. L., Hooper, D. U., Lavorel, S., Sala, O. E., Hobbie, S. E., Mack, M. C., \& Díaz, S. (2000). Consequences of changing biodiversity. Nature, 405, 234. https://doi.org/10.1038/35012241 
Chen, I.-C., Hill, J. K., Ohlemüller, R., Roy, D. B., \& Thomas, C. D. (2011). Rapid Range Shifts of Species Associated with High Levels of Climate Warming. Science, 333(6045), 1024 LP - 1026. https://doi.org/10.1126/science. 1206432

Chesson, P. (2000). Mechanisms of Maintenance of Species Diversity. Annual Review of Ecology and Systematics, 31, 343-366. https://doi.org/10.2307/221736

Clavel, J., Julliard, R., \& Devictor, V. (2011). Worldwide decline of specialist species: toward a global functional homogenization? Frontiers in Ecology and the Environment, 9(4), 222228. https://doi.org/10.1890/080216

Collins, S. L., Suding, K. N., Cleland, E. E., Batty, M., Pennings, S. C., Gross, K. L., Grace, J. B., Gough, L., Fargione, J. E., \& Clark, C. M. (2008). Rank clocks and plant community dynamics. Ecology, 89(12), 3534-3541. https://doi.org/10.1890/07-1646.1

Connell, J. H. (1978). Diversity in tropical rainforests and coral reefs. Science, 199, 1302-1310.

Conrad, K. F., Warren, M. S., Fox, R., Parsons, M. S., \& Woiwod, I. P. (2006). Rapid declines of common, widespread British moths provide evidence of an insect biodiversity crisis. Biological Conservation, 132(3), 279-291. https://doi.org/https://doi.org/10.1016/j.biocon.2006.04.020

Dennis, E. B., Brereton, T. M., Morgan, B. J. T., Fox, R., Shortall, C. R., Prescott, T., \& Foster, S. (2019). Trends and indicators for quantifying moth abundance and occupancy in Scotland. Journal of Insect Conservation, 23(2), 369-380. https://doi.org/10.1007/s10841019-00135-z

Dirzo, R., Young, H. S., Galetti, M., Ceballos, G., Isaac, N. J. B., \& Collen, B. (2014). Defaunation in the Anthropocene. Science, 345(6195), 401-406. https://doi.org/10.1126/science.1251817 
Donohue, I., Hillebrand, H., Montoya, J. M., Petchey, O. L., Pimm, S. L., Fowler, M. S., Healy, K., Jackson, A. L., Lurgi, M., McClean, D., O’Connor, N. E., O’Gorman, E. J., \& Yang, Q. (2016). Navigating the complexity of ecological stability. Ecology Letters, 19(9), 11721185. https://doi.org/10.1111/ele. 12648

Donohue, I., Petchey, O. L., Montoya, J. M., Jackson, A. L., McNally, L., Viana, M., Healy, K., Lurgi, M., O’Connor, N. E., \& Emmerson, M. C. (2013). On the dimensionality of ecological stability. Ecology Letters, 16(4), 421-429. https://doi.org/10.1111/ele.12086

Fleishman, E., \& Murphy, D. D. (2009). A Realistic Assessment of the Indicator Potential of Butterflies and Other Charismatic Taxonomic Groups . Conservation Biology.

Fox, R. (2013). The decline of moths in Great Britain: a review of possible causes. Insect Conservation and Diversity, 6(1), 5-19. https://doi.org/10.1111/j.1752-4598.2012.00186.x

Franklin, J. F. (1989). Importance and Justification of Long-Term Studies in Ecology BT - LongTerm Studies in Ecology: Approaches and Alternatives (G. E. Likens (ed.); pp. 3-19). Springer New York. https://doi.org/10.1007/978-1-4615-7358-6_1

Franzén, M., \& Johannesson, M. (2007). Predicting extinction risk of butterflies and moths (Macrolepidoptera) from distribution patterns and species characteristics. Journal of Insect Conservation, 11(4), 1572-1593.

Gotelli, N. J., \& Colwell, R. K. (2001). Quantifying biodiversity: procedures and pitfalls in the measurement and comparison of species richness. Ecology Letters, 4(4), 379-391. https://doi.org/10.1046/j.1461-0248.2001.00230.x

Groenendijk, D., \& Ellis, W. N. (2011). The state of the Dutch larger moth fauna. Journal of Insect Conservation, 15(1), 95-101. https://doi.org/10.1007/s10841-010-9326-y

Hill, J. K., Thomas, C. D., Fox, R., Telfer, M. G., Willis, S. G., Asher, J., \& Huntley, B. (2002). 
Responses of butterflies to twentieth century climate warming: implications for future ranges. Proceedings of the Royal Society of London. Series B: Biological Sciences, 269(1505), 2163-2171. https://doi.org/10.1098/rspb.2002.2134

Hillebrand, H., Langenheder, S., Lebret, K., Lindström, E., Östman, Ö., \& Striebel, M. (2018). Decomposing multiple dimensions of stability in global change experiments. Ecology Letters, 21(1), 21-30. https://doi.org/10.1111/ele.12867

Hooper, D. U., Chapin, F. S., Ewel, J. J., Hector, A., Inchausti, P., Lavorel, S., Lawton, J. H., Lodge, D. M., Loreau, M., Naeem, S., Schmid, B., Setala, H., Symstad, A. J., Vandermeer, J., \& Wardle, D. A. (2005). Effects of biodiversity on ecosystem functioning: A consensus of current knowledge. Ecological Monographs, 75(1), 3-35.

Isbell, F. I., Polley, H. W., \& Wilsey, B. J. (2009). Biodiversity, productivity and the temporal stability of productivity: patterns and processes. Ecology Letters, 12(5), 443-451. https://doi.org/10.1111/j.1461-0248.2009.01299.x

Keppel, G., Van Niel, K. P., Wardell-Johnson, G. W., Yates, C. J., Byrne, M., Mucina, L., Schut, A. G. T., Hopper, S. D., \& Franklin, S. E. (2012). Refugia: identifying and understanding safe havens for biodiversity under climate change. Global Ecology and Biogeography, 21(4), 393-404. https://doi.org/10.1111/j.1466-8238.2011.00686.x

Kerr, J. T., Sugar, A., \& Packer, L. (2000). Indicator taxa, rapid biodiversity assessment, and nestedness in an endangered ecosystem. Conservation Biology, 14(6), 1726-1734. https://doi.org/10.1111/j.1523-1739.2000.99275.x

Kitahara, M., \& Fujii, K. (1994). Biodiversity and community structure of temperate butterfly species within a gradient of human disturbance: An analysis based on the concept of generalist vs. Specialist strategies. Population Ecology, 36(2), 187. 
https://doi.org/10.1007/BF02514935

Kristensen, N. P., Scoble, M. J., \& Karsholt, O. L. E. (2007). Lepidoptera phylogeny and systematics: the state of inventorying moth and butterfly diversity. Zootaxa, 1668(1), 699747.

Layer, K., Riede, J. O., Hildrew, A. G., \& Woodward, G. (2010). Chapter 5 - Food Web Structure and Stability in 20 Streams Across a Wide pH Gradient. In G. B. T.-A. in E. R. Woodward (Ed.), Ecological Networks (Vol. 42, pp. 265-299). Academic Press. https://doi.org/https://doi.org/10.1016/B978-0-12-381363-3.00005-8

Lindenmayer, D. B., \& Likens, G. E. (2009). Adaptive monitoring: a new paradigm for longterm research and monitoring. Trends in Ecology \& Evolution, 24(9), 482-486. https://doi.org/https://doi.org/10.1016/j.tree.2009.03.005

Losey, J. E., \& Vaughan, M. (2006). The Economic Value of Ecological Services Provided by Insects. BioScience, 56(4), 311-323. https://doi.org/10.1641/00063568(2006)56[311:TEVOES]2.0.CO;2

MacArthur, R. (1955). Fluctuations of Animal Populations and a Measure of Community Stability. Ecology, 36(3), 533-536. https://doi.org/10.2307/1929601

MacArthur, R. H., \& Wilson, E. O. (1967). The theory of island biogeography. Princeton University Press.

Magurran, A. E., Baillie, S. R., Buckland, S. T., Dick, J. M., Elston, D. A., Scott, E. M., Smith, R. I., Somerfield, P. J., \& Watt, A. D. (2010). Long-term datasets in biodiversity research and monitoring: assessing change in ecological communities through time. Trends in Ecology \& Evolution, 25(10), 574-582. https://doi.org/https://doi.org/10.1016/j.tree.2010.06.016 
Oliver, T. H., Heard, M. S., Isaac, N. J. B., Roy, D. B., Procter, D., Eigenbrod, F., Freckleton, R., Hector, A., Orme, C. D. L., Petchey, O. L., Proença, V., Raffaelli, D., Suttle, K. B., Mace, G. M., Martín-López, B., Woodcock, B. A., \& Bullock, J. M. (2015). Biodiversity and Resilience of Ecosystem Functions. Trends in Ecology \& Evolution, 30(11), 673-684. https://doi.org/https://doi.org/10.1016/j.tree.2015.08.009

Owen, D. F., \& Duthie, D. J. (1982). Britain's successful moth colonist: Blair's shoulder-knot Lithophane leautieri (noctuidae). Biological Conservation, 23(4), 285-290. https://doi.org/https://doi.org/10.1016/0006-3207(82)90084-2

Pennekamp, F., Pontarp, M., Tabi, A., Altermatt, F., Alther, R., Choffat, Y., Fronhofer, E. A., Ganesanandamoorthy, P., Garnier, A., Griffiths, J. I., Greene, S., Horgan, K., Massie, T. M., Mächler, E., Palamara, G. M., Seymour, M., \& Petchey, O. L. (2018). Biodiversity increases and decreases ecosystem stability. Nature, 563(7729), 109-112. https://doi.org/10.1038/s41586-018-0627-8

R Core Team. (2019). R: A Language and Environment for Statistical Computing. R Foundation for Statistical Computing. http://www.r-project.org

Scheffers, B. R., Joppa, L. N., Pimm, S. L., \& Laurance, W. F. (2012). What we know and don't know about Earth's missing biodiversity. Trends in Ecology \& Evolution, 27(9), 501-510. https://doi.org/http://dx.doi.org/10.1016/j.tree.2012.05.008

Seymour, M., Edwards, F., Cosby, J., Scarlet, P., Bista, I., Brailsford, F., Glanville, H., Bruyn, M. de, Carvalho, G., \& Creer, S. (2020). Nestedness and turnover of riverine species and functional diversity using eDNA and traditional approaches. Research Square. https://doi.org/10.21203/rs.3.rs-82612/v2

Seymour, M., Perera, O. P., Fescemyer, H. W., Jackson, R. E., Fleischer, S. J., \& Abel, C. A. 
(2016). Peripheral genetic structure of Helicoverpa zea indicates asymmetrical panmixia. Ecology and Evolution, 6(10), 3198-3207. https://doi.org/ece3.2106

Tilman, D., Reich, P. B., \& Knops, J. M. H. (2006). Biodiversity and ecosystem stability in a decade-long grassland experiment. Nature, 441(7093), 629-632. https://doi.org/10.1038/nature04742

Usher, M. B., \& Keiller, S. W. J. (1998). The macrolepidoptera of farm woodlands: determinants of diversity and community structure. Biodiversity \& Conservation, 7(6), 725-748. https://doi.org/10.1023/A:1008836302193

Waring, P., \& Townsend, M. (2017). Field guide to the moths of Great Britain and Ireland (3rd ed.). Bloomsbury Publishing Plc.

Willis, K. J., Araújo, M. B., Bennett, K. D., Figueroa-Rangel, B., Froyd, C. A., \& Myers, N. (2007). How can a knowledge of the past help to conserve the future? Biodiversity conservation and the relevance of long-term ecological studies. Philosophical Transactions of the Royal Society B: Biological Sciences, 362(1478), 175 LP - 187. http://rstb.royalsocietypublishing.org/content/362/1478/175.abstract

Wood, S. N. (2011). Fast stable restricted maximum likelihood and marginal likelihood estimation of semiparametric generalized linear models. Journal of the Royal Statistical Society: Series B (Statistical Methodology), 73(1), 3-36. https://doi.org/10.1111/j.14679868.2010.00749.x

Young, M. (1997). The natural history of moths. A\&C Black. 
Table 1. Total number of moths per family captured from 1993 to 2014 at Treborth Botanic Garden, North Wales, UK.

\begin{tabular}{lr}
\hline Family & Number of species \\
\hline Drepanidae & 9 \\
Erebidae & 26 \\
Geometridae & 153 \\
Hepialidae & 5 \\
Lasiocampidae & 5 \\
Noctuidae & 176 \\
Nolidae & 3 \\
Notodontidae & 11 \\
Sesiidae & 1 \\
Sphingidae & 8 \\
\hline
\end{tabular}


Table 2. Statistics for the GAM model explaining the interactive effect of month, year and temperature on lepidopteran species richness, Fisher's alpha and Shannon diversity.

\section{Species richness}

\begin{tabular}{lllll}
\hline (Intercept) & $\begin{array}{l}\text { Estimate } \\
49.96\end{array}$ & $\begin{array}{l}\text { SE } \\
0.78\end{array}$ & $\begin{array}{l}\text { T-value } \\
64.03\end{array}$ & $\begin{array}{l}\text { P-value } \\
<0.001\end{array}$ \\
\hline Approximate significance of smooth terms: & & & & \\
& Edf & Ref.df & F & $\begin{array}{l}\text { p-value } \\
\text { s(Month, Year, Temperature) }\end{array}$ \\
& 67 & 84.27 & 33.27 & $<0.001$ \\
R-sq.(adj) $=0.917$ Deviance explained $=$ & & & & \\
$93.9 \%$ & & & & \\
\hline
\end{tabular}

Fisher's alpha

\begin{tabular}{|c|c|c|c|c|}
\hline (Intercept) & $\begin{array}{l}\text { Estimate } \\
11.05\end{array}$ & $\begin{array}{l}\text { SE } \\
0.15\end{array}$ & $\begin{array}{l}\text { T-value } \\
72.02\end{array}$ & $\begin{array}{l}\text { P-value } \\
<0.001\end{array}$ \\
\hline \multicolumn{5}{|c|}{ Approximate significance of smooth terms: } \\
\hline s(Month, Year, Temperature) & $\begin{array}{l}\text { Edf } \\
67.1\end{array}$ & $\begin{array}{l}\text { Ref.df } \\
84.38\end{array}$ & $\begin{array}{l}F \\
35.38\end{array}$ & $\begin{array}{l}\text { P-value } \\
<0.001\end{array}$ \\
\hline \multicolumn{5}{|c|}{ R-sq. $(\operatorname{adj})=0.922$ Deviance explained $=94.3 \%$} \\
\hline \multicolumn{5}{|l|}{ Shannon diversity } \\
\hline (Intercept) & $\begin{array}{l}\text { Estimate } \\
2.36\end{array}$ & $\begin{array}{l}\text { SE } \\
0.28\end{array}$ & $\begin{array}{l}\text { T-value } \\
85.68\end{array}$ & $\begin{array}{l}\text { P-value } \\
<0.001\end{array}$ \\
\hline \multicolumn{5}{|c|}{ Approximate significance of smooth terms: } \\
\hline s(Month, Year, Temperature) & $\begin{array}{l}\text { Edf } \\
46.91\end{array}$ & $\begin{array}{l}\text { Ref.df } \\
61.69\end{array}$ & $\begin{array}{l}F \\
12.62\end{array}$ & $\begin{array}{l}\text { P-value } \\
<0.001\end{array}$ \\
\hline
\end{tabular}


Table 3. Final model statistics for the stability analyses with the stability metric presented for each test assessing the linear relationship between stability and species richness, feeding group (generalist, specialist) and mean annual temperature. Df, Degrees of freedom.

Stability (Inverse Mean Rank Shift)

\begin{tabular}{lrrrrr}
\hline Df & Df & SumSquares & MeanSumSq & F-value & \multicolumn{1}{c}{ P-value } \\
\hline Species richness & 1 & 230.1 & 230.1 & 5.18 & $\mathbf{0 . 0 2 9}$ \\
Feeding group & 1 & 451.96 & 452.0 & 10.17 & $\mathbf{0 . 0 0 3}$ \\
Temperature & 1 & 105.34 & 105.3 & 2.37 & 0.133
\end{tabular}

Stability (Temporal Variability)

\begin{tabular}{lrrrrr}
\hline Df & Df & SumSquares & MeanSumSq & F-value & \multicolumn{2}{c}{ P-value } \\
\hline Species richness & 1 & 0.82 & 0.82 & 12.10 & $\mathbf{0 . 0 0 1}$ \\
Feeding group & 1 & 28.56 & 28.56 & 423.17 & $<\mathbf{0 . 0 0 1}$ \\
Temperature & 1 & 0.19 & 0.19 & 2.86 & 0.1
\end{tabular}

Stability (Compositional Turnover)

\begin{tabular}{lrrrrr}
\hline Df & Df & SumSquares & MeanSumSq & F-value & \multicolumn{1}{c}{ P-value } \\
\hline Species richness & 1 & 0.0005 & 0.001 & 0.39 & 0.537 \\
Feeding group & 1 & 0.0477 & 0.048 & 34.42 & $<\mathbf{0 . 0 0 1}$ \\
Richness x group & 1 & 0.0041 & 0.004 & 3.07 & 0.089
\end{tabular}


Fig. 1. Lepidopteran species richness (top panel), Fisher's alpha (middle panel) and Shannon diversity (bottom panel) over time. GAM model (with monthly temperature included as a smoothing term) predicted model fits (yellow line) to predict the observed moth species or diversity (black line) patterns over the 20-year observation period (y-axis).

Fig. 2. Rank clock figures to show the change in rank abundances with rank 1 (most abundant) furthest from the center and rank 250 (least abundant) at the clock center. Center panel: each line represents the temporal ranking of a unique species $(\mathrm{N}=376)$ from 1994 to 2013 , moving clockwise on the graph. Grey circles and corresponding numbers indicate rank locations for ranks 50, 100 and 250. Line colors show the variability in generalist (blue) and specialist (yellow) species. Each outer panel has the same scale as the middle panel and highlights a unique species (label in top left). The top row (blue background) are examples of the most dominant species throughout the monitoring period. The other eight panels show species with high variability in rank abundances over the monitoring period.

Fig. 3. (A) Community stability calculated as inverse mean rank shift versus mean species richness; (B) Stability calculated as temporal variability versus mean annual species richness; (C) Stability calculated as compositional turnover (1-Jaccard dissimilarity index) versus mean annual species richness. In panel (A), error bars correspond to the 1.5 times interquartile range. In panels (A), (B) and (C) the solid lines are the fitted curves from the corresponding linear regression models and colors correspond to generalist (blue) and specialist (orange) feeding groups. 
Fig. 4. Mean (annual) species rank (x-axis) versus standard deviation in mean species rank (yaxis). Colors correspond to polyphagous (blue) and mono/oligophagous (orange) feeding groups. 
Fig. 1.
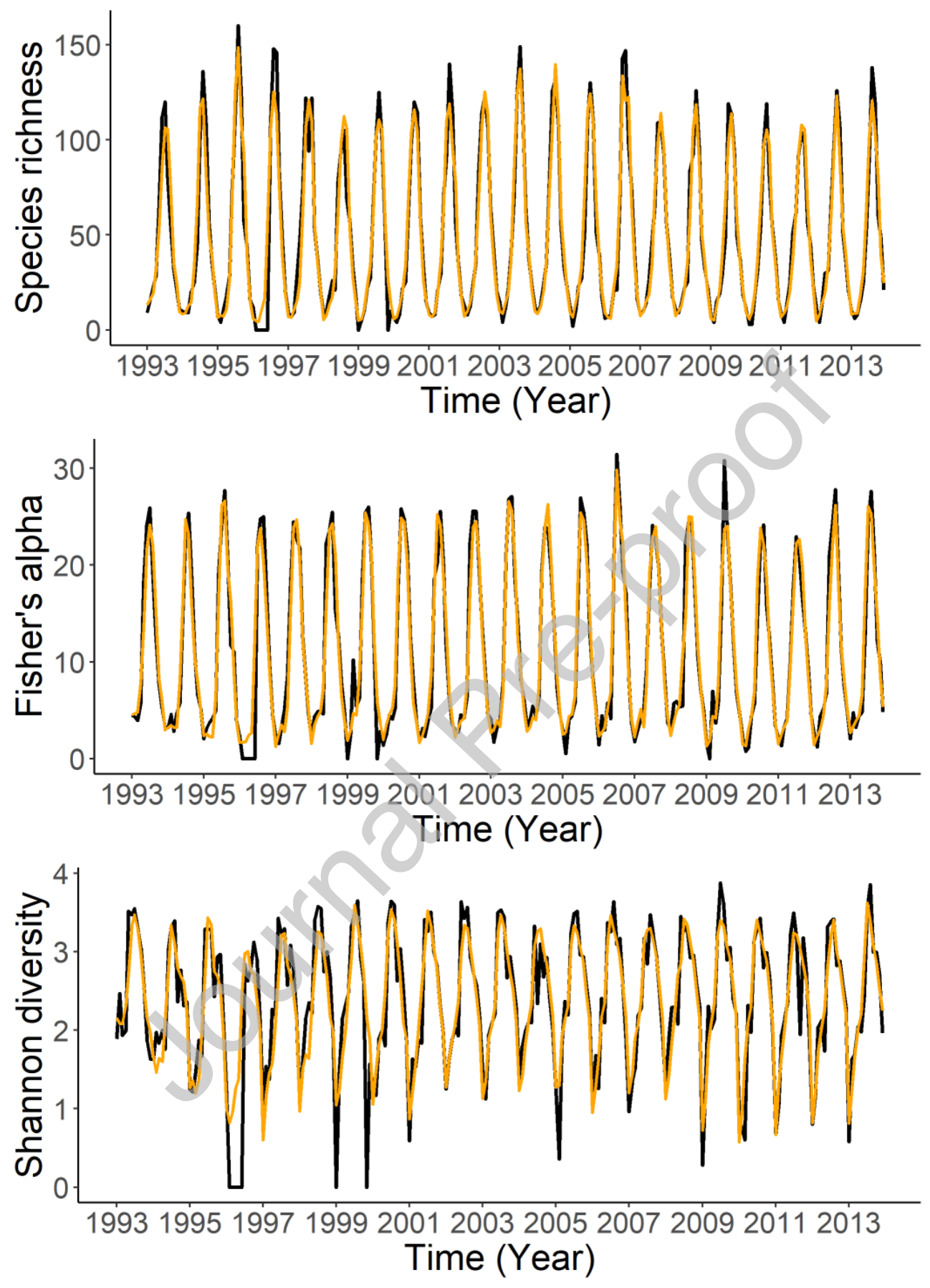
Fig. 2.
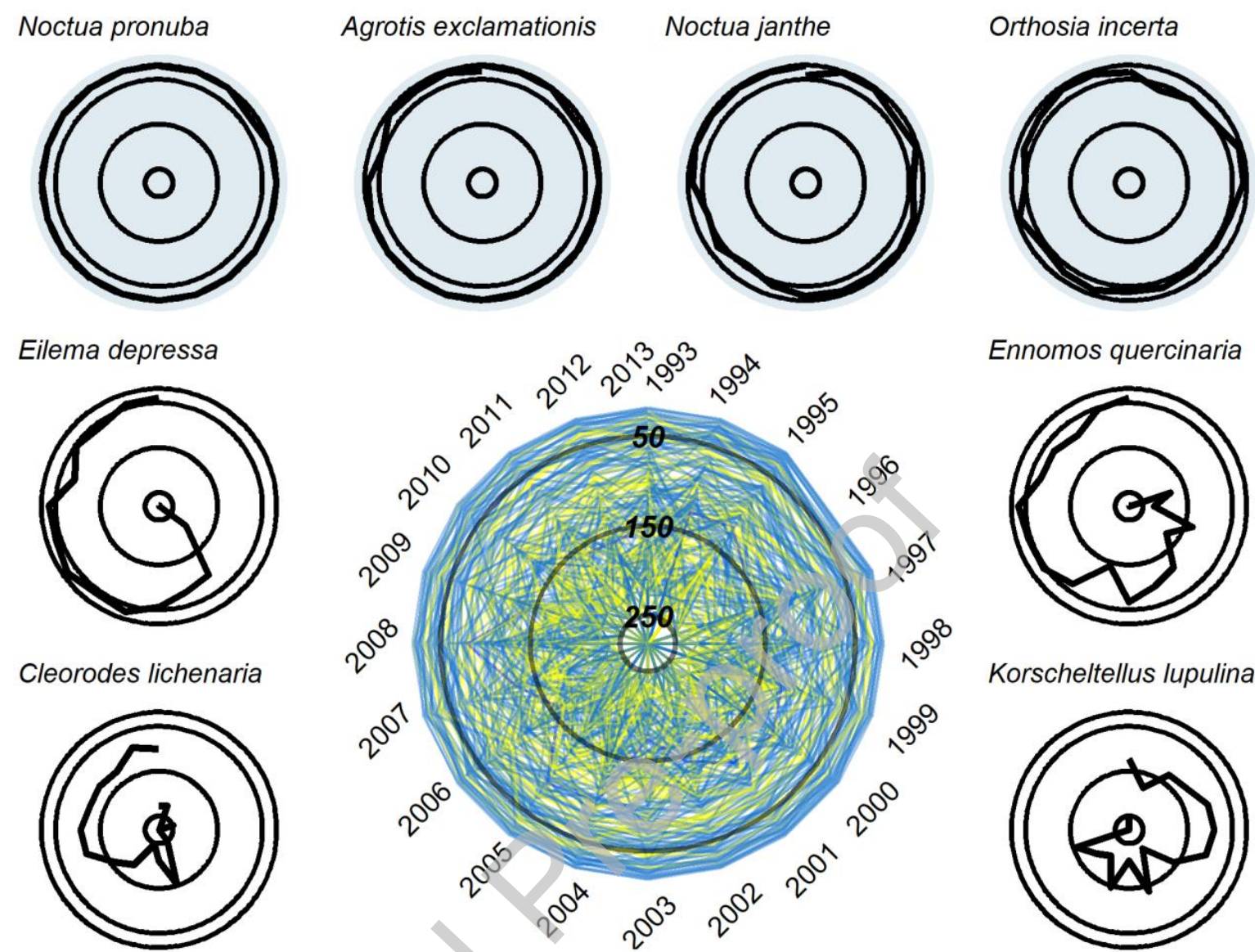

Ennomos quercinaria

Cleorodes lichenaria

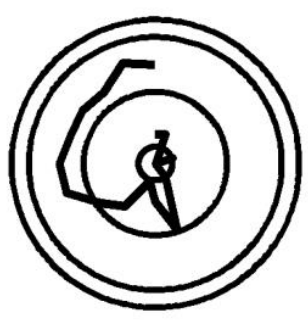

Leucania comma

Lacanobia oleracea

Acontia lucida

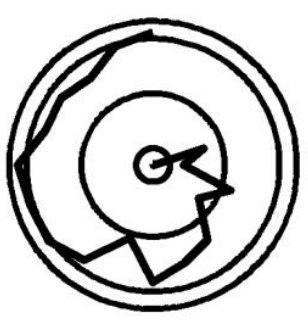

Korscheltellus Iupulina
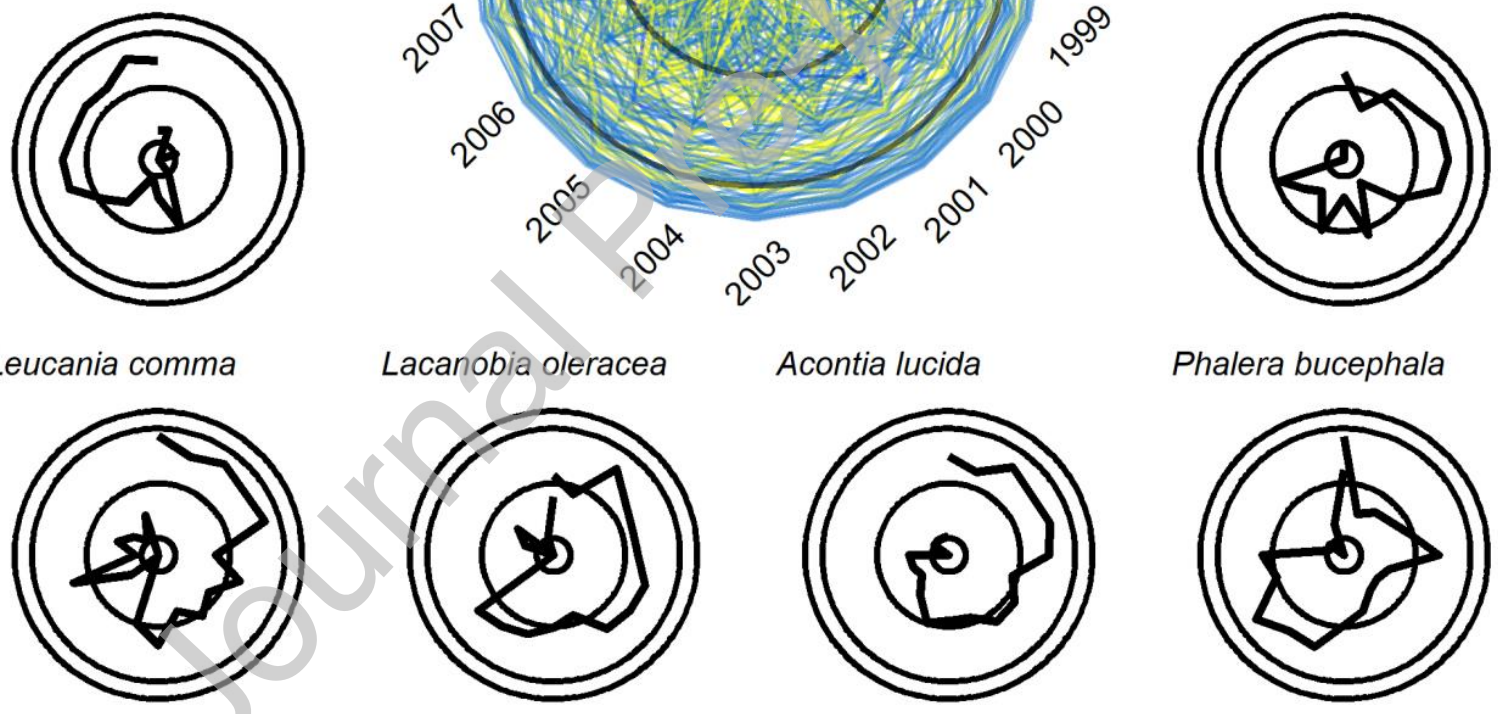

Phalera bucephala

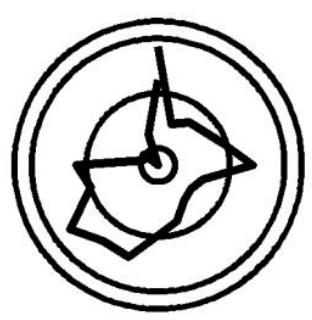


Fig. 3.
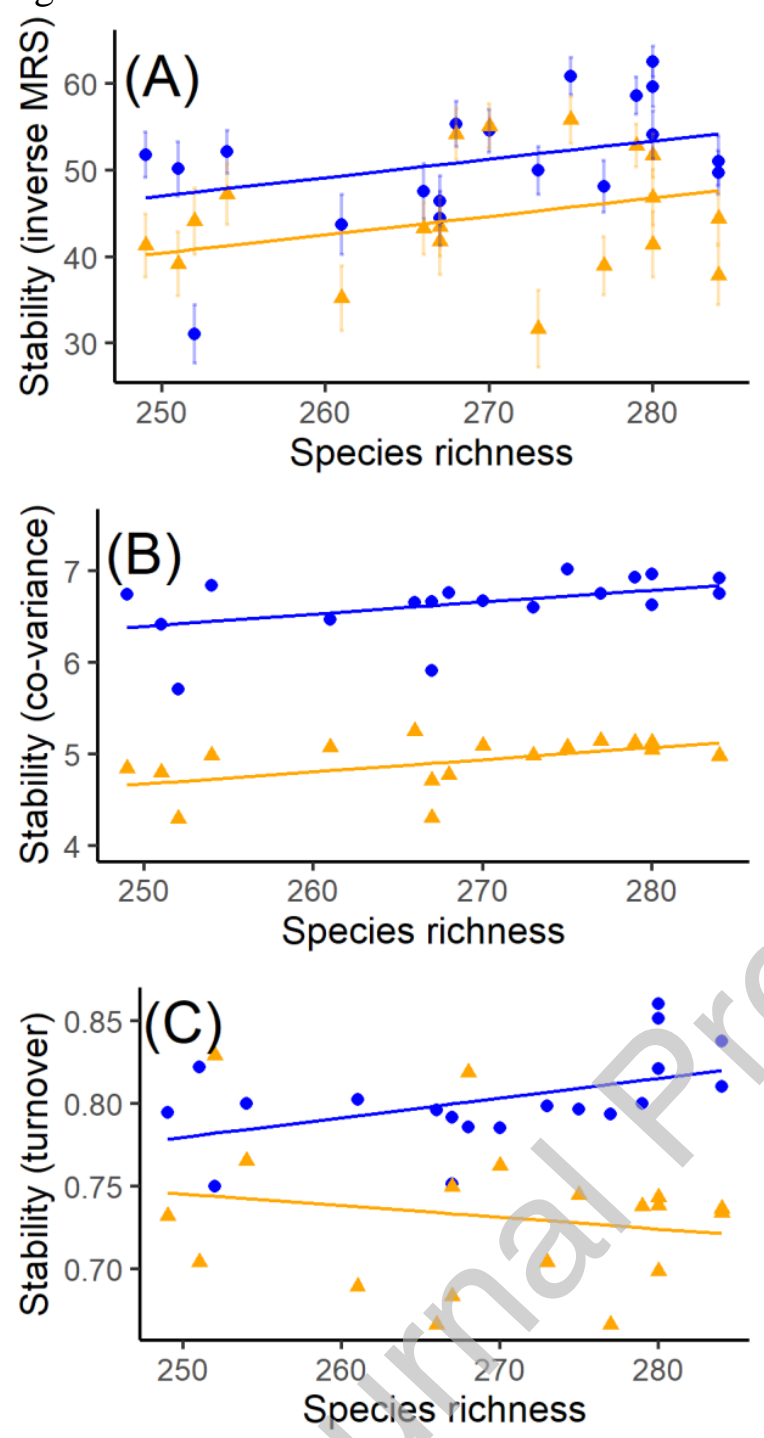
Fig. 4.

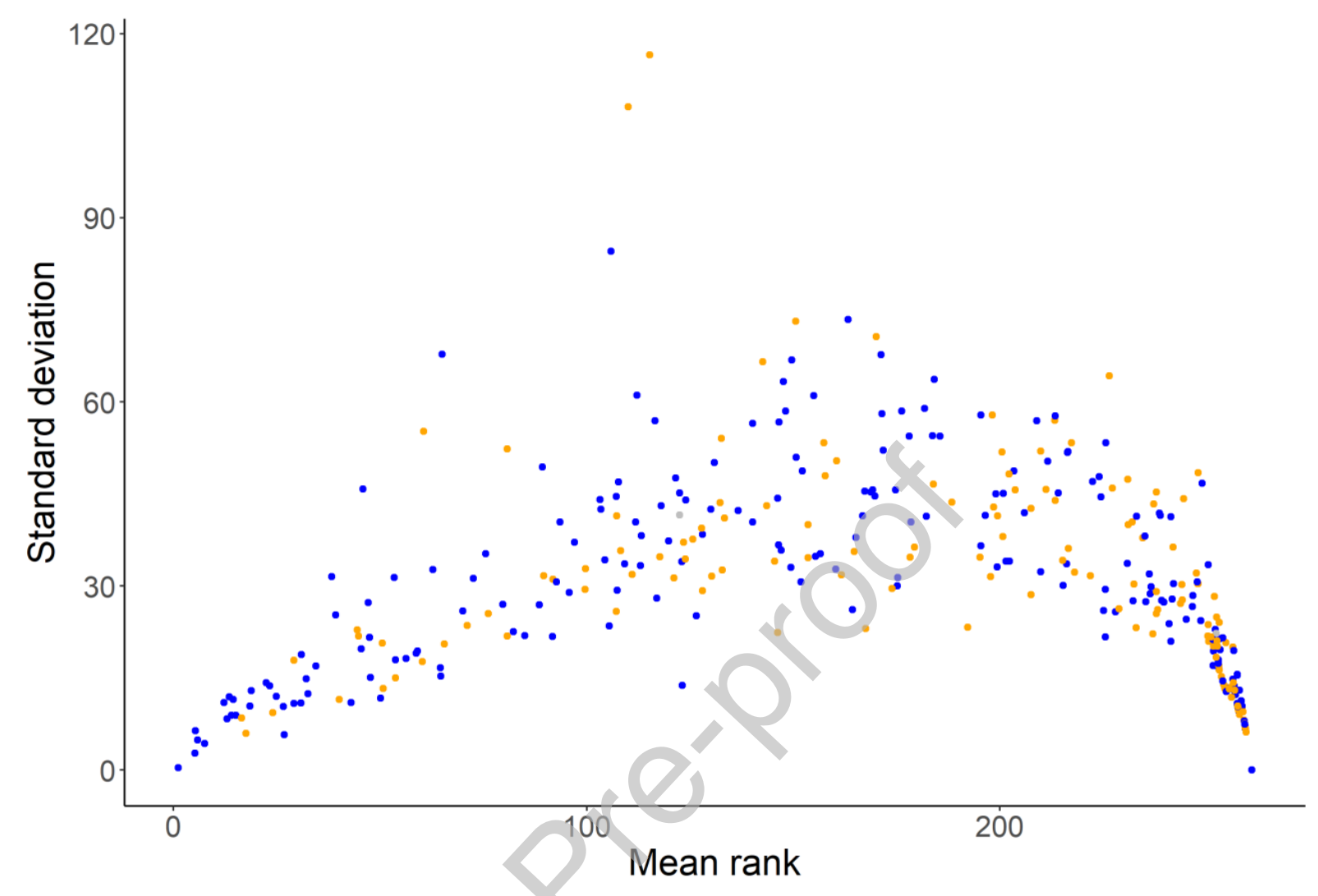

